\title{
Phytochemical extraction and quantification from wild pomegranate flavedo powder, their antioxidant and antimicrobial properties
}

\author{
Hamid`, N. S. Thakur, Rakesh Sharma, Abhimanyu Thakur, Pradeep Kumar and Sunakshi Gautam \\ Department of Food Science and Technology, Dr Yashwant Singh Parmar University of Horticulture and Forestry, Nauni, Solan, Himachal \\ Pradesh 173230, India
}

\section{Article Info}

Article history

Received 12 Decmber 2019

Revised 30 January 2020

Accepted 5 February 2020

Published online 30 June 2020

Keywords

Antibacterial effects

FRAP

Natural antioxidants

Phenolics

Wild pomegranate flavedo powder

\begin{abstract}
In present study wild pomegranate flavedo powder $(425 \mu$ particle size) was used for the extraction of phenolics through various solvents by Soxhlet method. A significant difference in all parameters was observed among the different extracts with varying solvents and extraction time after oven drying of extracts. The highest total phenolics and flavonoids among different extracts after oven drying were recorded when ethanol was used as solvent after $6 \mathrm{~h}$ of extraction. To separate different treatments based on similarity, cluster analysis was applied based on Ward method and it showed that all treatments were divided in nine major groups and two major clusters. The two best selected extracts were further compared on the basis of total phenolics, flavonoids and various antioxidant properties after lyophilization. In conclusion, lyophilized ethanolic extract $(4 \mathrm{~h})$ contained higher total phenolics $(174.62 \mathrm{GAE} / \mathrm{g})$, flavonoids $(8.90 \mathrm{QuE} / \mathrm{g})$, DPPH free radical scavenging activity $(88.12 \%)$, ferric reducing antioxidant power $(816.10 \mu \mathrm{M}$ $\left.\mathrm{Fe}^{2+} / 100 \mathrm{~g}\right)$ and metal chelating activity $(68.50 \%)$. The selected lyophilized extract has also shown higher zone of inhibition against $S$. aureus and E. coli as $22.0 \mathrm{~mm}$ and $20.0 \mathrm{~mm}$ at $100 \mathrm{ppm}$ concentration. Hence, fruit flavedo is rich source of total phenolics, total flavonoids and antioxidant activity which are beneficial natural antioxidants to health and have many health promoting properties which makes the flavedo suitable for future processing into various functional/nutraceutical foods.
\end{abstract}

\section{Introduction}

Wild pomegranate (Punica granatum L.) is an important wild fruit of Himachal with great economic significance. In India, it is naturally found growing in hill slopes of Himachal Pradesh, Jammu and Kashmir and Uttarakhand at an altitude of 900 to $1800 \mathrm{~m}$ above mean sea level. Higher organic acid content is one of the unique characteristics of wild pomegranate fruit, besides have been known for thick rinds than commercial one (Kher, 1999). Its fruit is also good source of anthocyanins, phenolics, flavonoids and vitamins (Thakur et al., 2018). In recent years, the demand for natural products containing natural antioxidants got increased due to recognition as a great source of health promoting constituents. Its fruit constitute three portions like albedo, flavedo and arils. Due to highly acidic nature of fruit arils, it is being processed into dried product known as 'anardana', because of the intense sourness. This dried product prepared by rural peoples of HP, J\&K and Uttarakhand is sold every year in tones in local markets as Rupees 200 to 600 per kg, along with it generates tones of by-products as flavedo (rind). The

Corresponding author: Dr. Hamid Department of Food Science and Technology, Dr Yashwant Singh Parmar University of Horticulture and Forestry, Nauni, Solan, Himachal Pradesh 173230, India

E-mail: hamidfst6789@gmail.com

Tel.: +91-7018820897

Copyright (C) 2020 Ukaaz Publications. All rights reserved.

Email: ukaaz@yahoo.com; Website: www.ukaazpublications.com rind (flavedo) also has good medicinal value and is used by India's herbal industry (Murtaza and Ahmad, 2017). Polyphenols mainly ellagitannins and ellagic acid are abundant in peel and responsible for the antioxidant, antimutagenic, anticancer, anti-inflammatory and antidiabetic effects (Masci et al., 2016). Its traditional uses, however, include preparing of ink for writing on 'Takhti' by school children, in dying leather, for making FYM by mixing with cattle dung (Murtaza and Ahmad, 2017). But in some areas, dried flavedo is being used for curing cough with honey as a traditional remedy. However, its commercial potential is yet to be tapped because of the non-availability of the drier and preserving the rind within short time. Because of this, besides arils other parts of the fruits are still unexplored for their antioxidant potential and they can also be utilized for preparation of various functional foods due to presence of higher antioxidants. Thus, flavedo portion of this fruit which constitute 50 percent of the fruit is rich source of natural polyphenolic antioxidants, could be utilized for the extraction of phenolics. The possible toxicity of synthetic antioxidants has led considerable attention toward natural antioxidants from plants for protecting against various diseases induced by free radicals. So, polyphenols utilization under permissible limits in products is likely to generate beneficial health effects. Despite its potential, studies on extraction of phenolics from flavedo of this wild plant species are almost lacking. Therefore, keeping in view its nutritive value in the present study, the extraction conditions of phenolic compounds using Soxhlet method from wild pomegranate flavedo 
were standardized and further selected extracts were compared after drying in oven and lyophilizer for retention of maximum antioxidants. Antimicrobial activity of extracts after lyophilization at different concentrations was also examined and a relationship was established between these activities and the phenolics and flavonoids contents. So that, these type of extracts were used in supplementation of food with bioactive compounds as well as helps in waste reduction.

\section{Materials and Methods}

\subsection{Collection of raw material}

Wild pomegranate fruits were procured at optimum maturity from Karsog location of Himachal Pradesh in the month of October 2017-18. After harvesting, fruits were transported to the laboratory through a well-ventilated vehicle on the same day and stored at $0^{\circ} \mathrm{C}$ till analysis. The flavedo (peel) from fruits were further separated and dried in mechanical cabinet $\operatorname{drier}\left(50^{\circ} \mathrm{C}\right)$.

\subsection{Extraction, concentration and drying methods}

The mechanical dried flavedo was further utilized for making flavedo powder by pulverizer having particle size of 425 microns through 36 mesh metallic sieve. The prepared flavedo powder was further used for extraction of phenolics through Soxhlet apparatus over water bath (Table 1). In this method of extraction, $10 \mathrm{~g}$ of flavedo powder was put in thimble under Soxhlet apparatus with $200 \mathrm{ml}$ of varying extraction solvents (ethanol, acetone, ethyl acetate and diethyl ether) and time $(2,4,6 \mathrm{~h})$. The extract obtained was further concentrated in vacuum rotatory evaporator $\left(\right.$ at $50^{\circ} \mathrm{C}$ ) until $1 / 4^{\text {th }}$ of the initial volume remained followed by oven drying $\left(50^{\circ} \mathrm{C}\right)$ of extract. The best treatment with higher phenolics content was further freeze-dried using a lyophilizer (LABCONCO-Free Zone USA) at a constant temperature of $-30^{\circ} \mathrm{C}$ with 0.04 mbar vacuum pressure upto a constant weight. The chemicals used during the entire study were of analytical grade and reference standard gallic acid and quercetin were procured from Sigma-Aldrich.

Table 1: Detail of treatments for extraction of phenolics by Soxhlet method

\begin{tabular}{|c|c|c|c|c|}
\hline Sr. No. & Solvents & \multicolumn{3}{|c|}{ Extraction time (h) } \\
\hline 1 & Ethanol & 2.0 & 4.0 & 6.0 \\
2 & Acetone & 2.0 & 4.0 & 6.0 \\
3 & Ethyl acetate & 2.0 & 4.0 & 6.0 \\
4 & Diethyl ether & 2.0 & 4.0 & 6.0 \\
\hline
\end{tabular}

\subsection{Physical characteristics}

Colour of samples was measured by a Lovibond Colour Tintometer Model PFX-1 series spectrophotometer, in which RYBN colour units were obtained along with CIE readings i.e. $\mathrm{L}^{*}, \mathrm{a}^{*}$ and $\mathrm{b}^{*}$ values. The $\mathrm{L}^{*}$ value gives a measure of the lightness of the product colour from 100 to 0,100 for perfect white while 0 for black. The $a^{*}$ value represents the green to red colour range and $b^{*}$ values represents yellow to blue colour range. The time taken to dry a given tray load was calculated by recording the time (h) required by the material in the tray till it attains a constant weight after drying in respective drying modes. Total extract yield was calculated by dividing the weight of dried material by the weight of fresh material multiplying by 100 .

\subsection{Chemical characteristics}

Total phenols content was determined by Folin-Ciocalteu procedure given by Singleton and Rossi (1965) in which absorbance was measured at $765 \mathrm{~nm}$ in a spectrophotometer (Model UV-1650 PC Shimadzu, Japan) against water blank. A standard calibration curve of gallic acid ( 20 to $100 \mu \mathrm{g} / \mathrm{ml}$ ) using its different concentrations was prepared. Total flavonoids content was estimated according to the method of Ilahy et al. (2011). DPPH (2, 2-Diphenyl-1picrylhydrazyl) free radical scavenging activity was measured as per the method of Brand-Williams et al. (1995). Reducing power was determined as per the method of Oktay et al. (2003) and absorbance of the sample extract at $700 \mathrm{~nm}$ was taken as a measure of reducing power. Metal chelating activity was determined according to the method of Dinis et al. (1994) and FRAP of the samples was estimated according to the method of Benzie and Strain (1996).

\subsection{Antimicrobial activity}

Antimicrobial activity of selected phenolic extracts against two test microorganisms, i.e., Escherichia coli (Gram negative bacteria) and Staphylococcus aurous (Gram positive bacteria) was detected by Well Diffusion method. A loopful culture of the test microorganisms was inoculated into $100 \mathrm{ml}$ of nutrient broth in $250 \mathrm{ml}$ Erlenmeyer flask. The test microorganisms were first grown in nutrient broth for $24-36 \mathrm{~h}$ at $37^{\circ} \mathrm{C}$. Wells of $6 \mathrm{~mm}$ diameter were cut into prepoured, sterilized nutrient agar petriplates with a sharp and sterile borer (6 $\mathrm{mm})$. Lawn of respective test micro-organism to be tested against the different phenolics extracts on these petriplates was prepared by pouring $0.1 \mathrm{ml}$ of inoculum and swabbing it properly with the help of sterilized cotton buds in such a way that test micro-organism cover whole of the nutrient agar plate. After that extracts of different concentrations of 25,50,75 and 100 ppm were prepared by dissolving phenolics extract, peel powder and microencapsulated powder in distilled water and keeping it overnight. After extract preparation different extracts were filled in already prepared $6 \mathrm{~mm}$ wells under laminar air flow. Then petriplates were incubated at $37^{\circ} \mathrm{C}$ for $24 \mathrm{~h}$ and results obtained were expressed in the form of zone of inhibition $(\mathrm{mm})$. The diameter of inhibition zone formed by extracts against the respective test microorganism was measured. In the same way, all the samples of phenolic extracts were tested against each test micro-organisms.

\subsection{Statistical analysis}

The data on physicochemical characteristics of extracts were analyzed by the Completely Randomized Design (CRD). One-way ANOVA with $(p<0.05)$ was used to analyze significant differences between treatments. Cluster analysis was performed by using ward method (SPSS). Different treatments of extraction by Soxhlet method were grouped into cluster form on the basis of similarities among extract yield, total phenolics content and total flavonoids content of respective solvents extract.

\section{Results}

The effect of extraction solvent and time on the extract yield, total phenolics and flavonoids of wild pomegranate flavedo extract have been highlighted in Figure 1(a-c), Table 2 and Table 3. A significant effect of extraction solvent and time on all the parameters was observed with varying solvent types. 


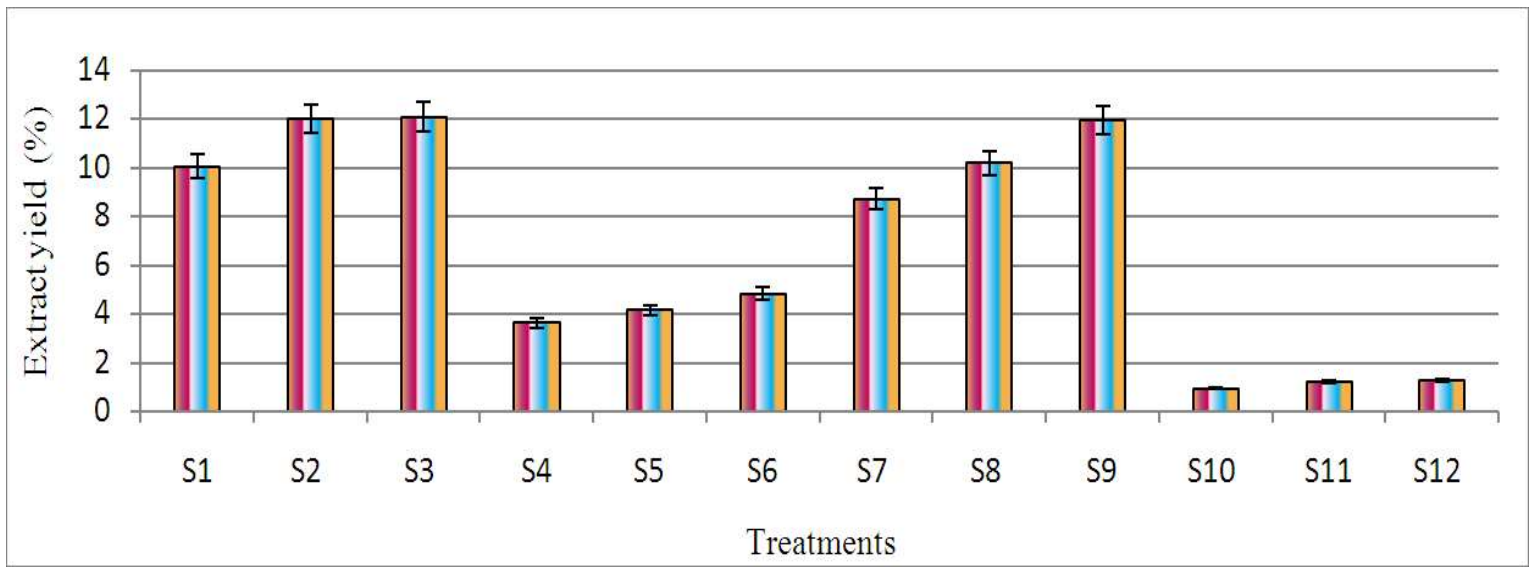

a. Extract yield (\%)

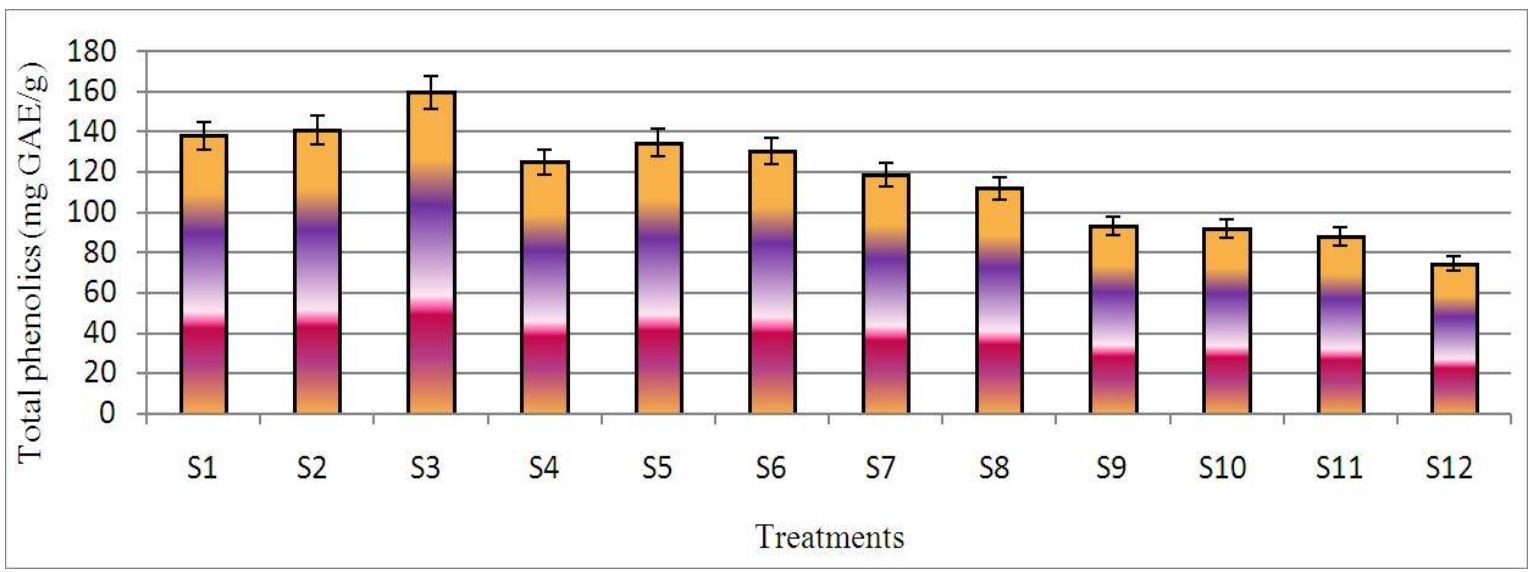

b. Total phenolics (mg GAE/g)

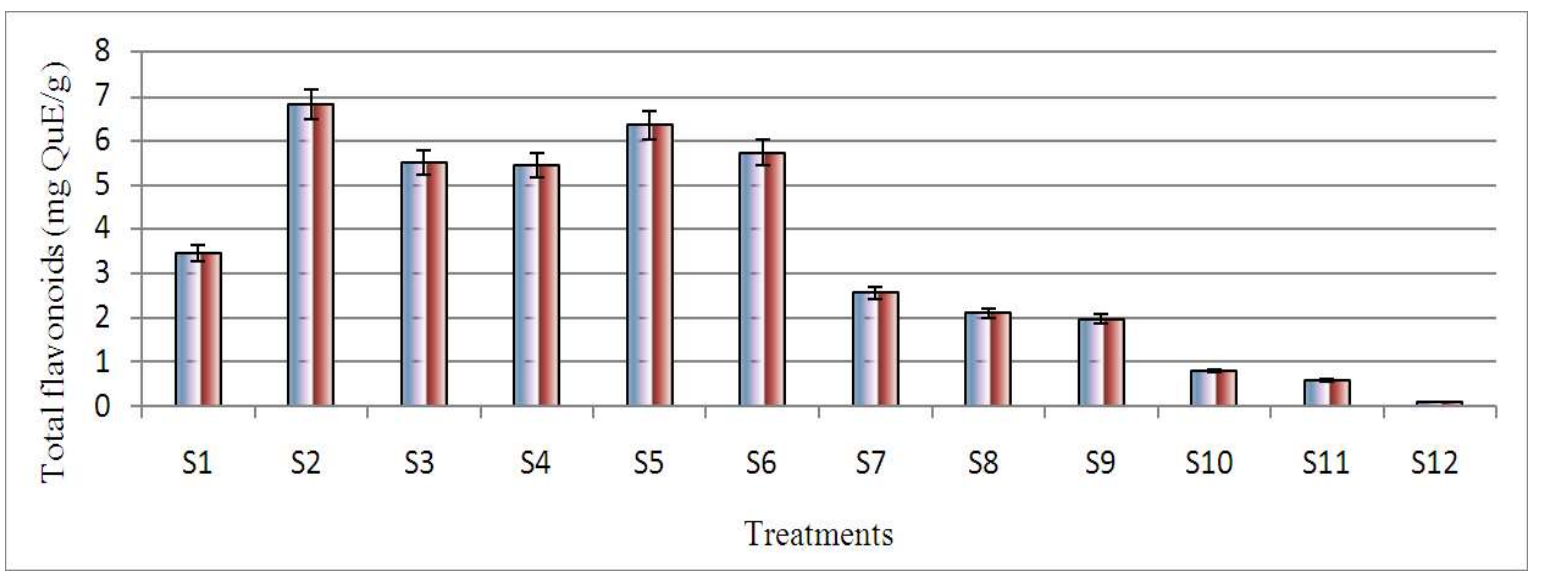

c. Total flavonoids (mg QuE/g)

Figure $1(\mathbf{a}, \mathbf{b}, \mathbf{c})$ : Effect of varying extraction time and solvents on extract yield, total phenolics and total flavonoids content $\left[\mathrm{S}_{1}\right.$ : Ethanol $(2 \mathrm{~h}), \mathbf{S}_{2}$ : Ethanol $(4 \mathrm{~h}), \mathbf{S}_{3}$ : Ethanol $(6 \mathrm{~h}), \mathbf{S}_{4}$ : Acetone $(2 \mathrm{~h}), \mathbf{S}_{5}$ : Acetone $(4 \mathrm{~h}), \mathbf{S}_{6}$ : Acetone $(6 \mathrm{~h}), \mathbf{S}_{7}$ : Ethyl acetate $(2 \mathrm{~h}), \mathbf{S}_{\mathbf{8}}$ : Ethyl acetate $(4 \mathrm{~h}), \mathbf{S}_{9}$ : Ethyl acetate $(6 \mathrm{~h}), \mathbf{S}_{10}$ : Diethyl ether $(2 \mathrm{~h}), \mathbf{S}_{11}$ : Diethyl ether $(4 \mathrm{~h}), \mathbf{S}_{12}$ : Diethyl ether $(6 \mathrm{~h})$ (values are average of triplicate replications and are represented as Mean $\pm \mathrm{SD})]$. 
Table 2: Extract yield, total phenolics and total flavonoids of oven dried and lyophilized phenolic extract powder of different treatments (values are average of triplicate replications and are represented as Mean $\pm \mathrm{SD}$ )

\begin{tabular}{|c|c|r|r|}
\hline Parameters & \multirow{2}{*}{ Treatments } & \multicolumn{2}{|c|}{ Drying modes } \\
\cline { 3 - 4 } & & $\mathbf{D}_{\mathbf{1}}$ & \multicolumn{1}{c|}{$\mathbf{D}_{\mathbf{2}}$} \\
\hline Extract yield & $\mathrm{T}_{1}$ & $12.00 \pm 0.04$ & $12.48 \pm 0.23$ \\
(\%) & $\mathrm{T}_{2}$ & $12.08 \pm 0.07$ & $12.92 \pm 0.40$ \\
\hline Total phenolics & $\mathrm{T}_{1}$ & $141.02 \pm 0.84$ & $174.62 \pm 0.98$ \\
(mg GAE/g) & $\mathrm{T}_{2}$ & $159.75 \pm 0.38$ & $171.05 \pm 0.50$ \\
\hline Total flavonoids & $\mathrm{T}_{1}$ & $6.81 \pm 0.90$ & $8.90 \pm 0.45$ \\
(mg QuE/g) & $\mathrm{T}_{2}$ & $5.50 \pm 0.20$ & $8.46 \pm 0.24$ \\
\hline
\end{tabular}

$\mathrm{T}_{1}$ : Ethanol extract of flavedo after $4 \mathrm{~h}$ of extraction by Soxhlet method,

$\mathrm{T}_{2}$ : Ethanol extract of flavedo after $6 \mathrm{~h}$ of extraction by Soxhlet method,

$\mathrm{D}_{1}$ : Oven dried phenolic extract powder, $\mathrm{D}_{2}$ : Lyophilized phenolic extract powder.

\subsection{Optimization of conditions for extraction of phenolics by Soxhlet method}

Figure 1(a-c) highlights the effect of extraction solvents and time on the total extract yield, total phenolics and flavonoids of wild pomegranate flavedo extract.

\subsubsection{Total extract yield}

Figure 1(a) shows that extract yield increased from 10.06 to 12.08 percent (ethanol), 3.63 to 4.84 percent (acetone), 8.72 to 11.94 percent (ethyl acetate) and 0.95 to 1.28 percent (diethyl ether) with the increase in extraction time. While comparing all the treatments, the extract yield increased with the increase in extraction time in all the solvents. However, the maximum extract yield (12.08\%) was observed after $6 \mathrm{~h}$ of extraction with ethanol $\left(\mathrm{S}_{3}\right)$ which was at par with $\mathrm{S}_{2}$ (ethanol, $4 \mathrm{~h}$ ) and minimum extract yield ( $0.95 \%$ ) was observed after $2 \mathrm{~h}$ of extraction with diethyl ether $\left(\mathrm{S}_{10}\right)$ which was closely followed by $\mathrm{S}_{11}$ and $\mathrm{S}_{12}$.

\subsubsection{Total phenolics}

Figure 1(b) revealed that total phenolics content increased with increasing extraction time when ethanol was used as solvent. This increase in total phenolics content was observed from 138.25 to $159.75 \mathrm{mg} \mathrm{GAE} / \mathrm{g}$ with increase in extraction time from 2 to $6 \mathrm{~h}$. When acetone was used as solvent, total phenolics content also increased from 125.20 to $134.69 \mathrm{mg} \mathrm{GAE} / \mathrm{g}$ with increase in extraction time from 2 to $4 \mathrm{~h}$, but further increase in extraction time led to decrease in total phenolics content. Figure 1(b) also show that total phenolics content decreased from 118.63 to $93.49 \mathrm{mg}$ $\mathrm{GAE} / \mathrm{g}$ and 92.18 to $74.56 \mathrm{mg} \mathrm{GAE} / \mathrm{g}$ with the increase in extraction time from 2 to $6 \mathrm{~h}$ when ethyl acetate and diethyl ether were used as solvents. While comparing all the treatments, total phenolics content increased with the increase in extraction time when ethanol was used as a solvent, but in all the other solvents, total phenolics content decreased with the increasing extraction time. However, the maximum total phenolics content was observed in ethanol $\left(\mathrm{S}_{3}\right)$ $(159.75 \mathrm{mg} \mathrm{GAE} / \mathrm{g})$ after $6 \mathrm{~h}$ of extraction and minimum total phenolics content (74.56 mg GAE/g) was observed in diethyl ether $\left(\mathrm{S}_{12}\right)$ after $6 \mathrm{~h}$ of extraction.

\subsubsection{Total flavonoids}

The Figure 1(c) indicates that total flavonoids content increased with the increase in extraction time from 2 to $4 \mathrm{~h}$ when ethanol was used as solvent. This increase in total flavonoids content was observed from 3.46 to $6.81 \mathrm{mg} \mathrm{QuE} / \mathrm{g}$ when extraction time increased from 2 to $4 \mathrm{~h}$ and, thereafter it decreased. Similar increasing trend in extraction of total flavonoids content was also recorded with the increase in extraction time from 2 to $4 \mathrm{~h}$ when acetone was used as a solvent, while it was observed to be decreased when extraction time further increased. This increase in total flavonoids content was observed from 5.44 to $6.35 \mathrm{mg} \mathrm{QuE} / \mathrm{g}$ when extraction time increased from 2 to $4 \mathrm{~h}$. When ethyl acetate and diethyl ether were used as solvent, the total flavonoids content decreased from 2.56 to $1.97 \mathrm{mg} \mathrm{QuE} / \mathrm{g}$ and 0.80 to $0.10 \mathrm{mg} \mathrm{QuE} / \mathrm{g}$ with increase in extraction time from 2 to $6 \mathrm{~h}$. While comparing all the treatments, the total flavonoids content increased with the increase in extraction time when ethanol and acetone were used as solvent, but in other solvents, total flavonoids content decreased with the increasing extraction time. However, the maximum $(6.81 \mathrm{mg} \mathrm{QuE} / \mathrm{g})$ total flavonoids content was observed in ethanol $\left(\mathrm{S}_{2}\right)$ after $4 \mathrm{~h}$ of extraction and minimum $(0.10 \mathrm{mg} \mathrm{QuE} / \mathrm{g})$ content was observed in diethyl ether $\left(\mathrm{S}_{12}\right)$ after $6 \mathrm{~h}$ of extraction.

\subsubsection{Hierarchical clustering}

Cluster analysis of different treatments of the phenolic extract was performed using rescaled distance cluster with respect to three parameters (total extract yield, total phenolics and total flavonoids). In cluster analysis or hierarchical clustering, samples are grouped on the basis of similarities without taking into account the information about the class membership. Cluster analysis calculates the distances (or correlation) between all samples using a defined metric (Berrueta et al., 2007). The results obtained from cluster analysis are shown as a dendrogram in Figure 2. All treatments were divided in seven major groups and two major clusters after the application of cluster analysis. The first group (1) was composed of treatments $\mathrm{S}_{10}, \mathrm{~S}_{11}, \mathrm{~S}_{4}$, in group (2) $\mathrm{S}_{9}$, in group (3) $\mathrm{S}_{12}$, in group (4) $\mathrm{S}_{7}, \mathrm{~S}_{8}$ and in group (5) $\mathrm{S}_{1}, \mathrm{~S}_{2}$, in group (6) $\mathrm{S}_{5}, \mathrm{~S}_{6}, \mathrm{~S}_{4}$, and in group (7) treatment $S_{3}$.

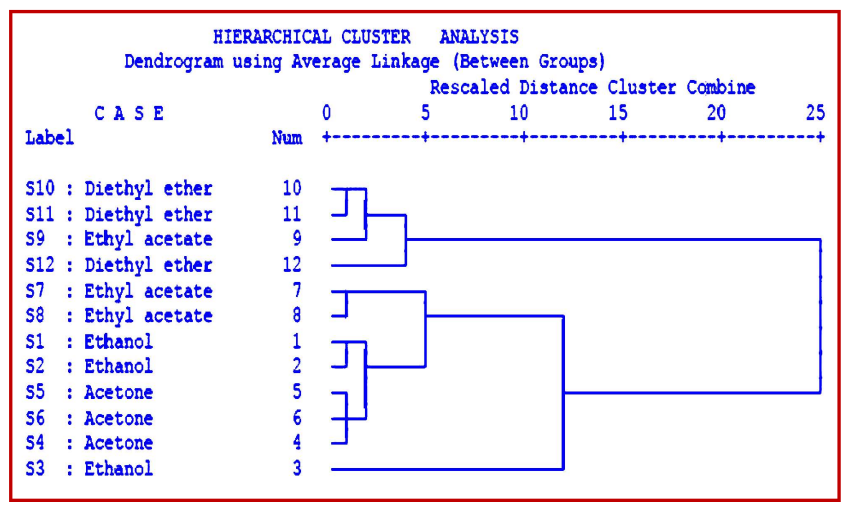

Figure 2: Dendrogram of extract yield, total phenolics and total flavonoids of phenolic extract prepared by Soxhlet method. 
3.2 Comparison of oven and freeze dried phenolic extract powder

The two best selected treatments $\left(\mathrm{S}_{2}, \mathrm{~S}_{3}\right)$ from Figure 1(a-c) were further compared on the basis of higher total phenolics and flavonoids content retention after oven $\left(50^{\circ} \mathrm{C}\right)$ drying and lyophilization. The significant differences were observed in drying time among both the treatments while comparing the oven dried $(3.40 \mathrm{~h}$ and $3.00 \mathrm{~h})$ and lyophilized phenolic extract powder $(64.20 \mathrm{~h}$ and $63.40 \mathrm{~h}$ ) of wild pomegranate flavedo. It took more time to dry the phenolic extract in lyophilizer as compared to oven. Data in Table 2 showed overall higher extract yield was observed in lyophilized samples as compare to oven dried samples. However, the maximum total phenolics and flavonoids content were also recorded in treatment $\mathrm{T}_{1}\left(\mathrm{~S}_{2}\right)$ as $174.62 \pm 0.98 \mathrm{mg} \mathrm{GAE} / \mathrm{g}$ and $8.90 \pm 0.45 \mathrm{mg} \mathrm{QuE} / \mathrm{g}$ after lyophilization of extract as compared to $\mathrm{T}_{2}\left(\mathrm{~S}_{3}\right)$. Data in Table 2 also reflect that total phenolics content and total flavonoids content were recorded higher in lyophilized samples of all the treatments as compare to oven dried samples.

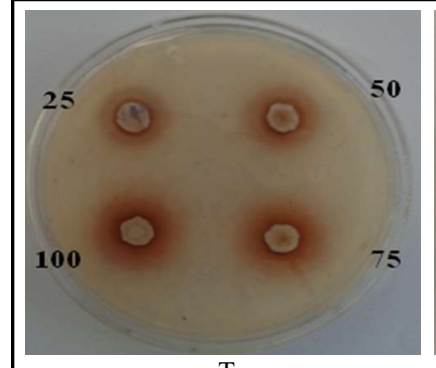

a. $\mathrm{T}_{1}$

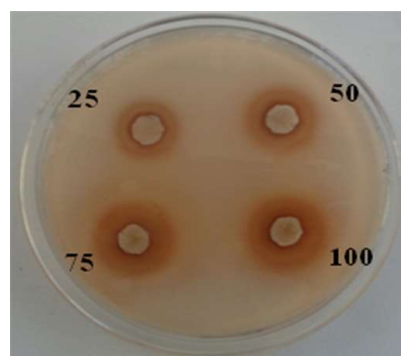

c. $\mathrm{T}_{1}$

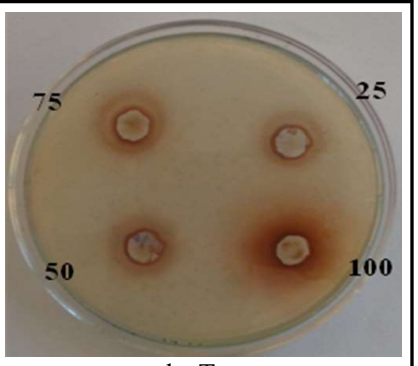

b. $\mathrm{T}_{2}$

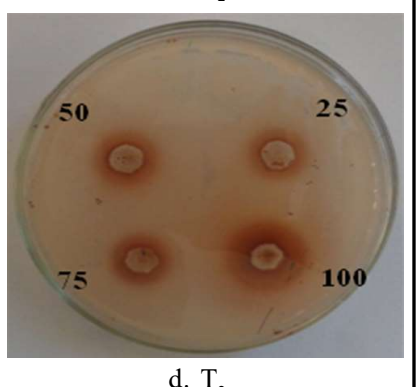

d. $\mathrm{T}_{2}$
Figure 3: Antimicrobial activity of wild pomegranate flavedo extract powder against Staphylococcus aureus $(\mathrm{a}, \mathrm{b})$ and Escherichia coli $(\mathrm{c}, \mathrm{d})$ at 25, 50, 75 and $100 \mathrm{ppm}$ concentration.
3.3 Colour and antioxidant properties of lyophilized phenolic extract powder

Due to higher phenolics in lyophilized extracts, these treatments were further selected for detailed comparison of antioxidant and colour properties (Table 3 ). Colour properties ( $\mathrm{L}^{*} \mathrm{a} * \mathrm{~b}^{*}$ values) and various antioxidant properties of lyophilized extract powder obtained after extraction are presented in Table 3 . The data of color values $\left(L^{*}, a^{*}, b^{*}\right)$ of phenolics extract powder show that higher $\mathrm{L}^{*}$ (Lightness) value as 91.27 was observed in $\mathrm{T}_{2}$, whereas, lower $\mathrm{L}^{*}$ value as 90.85 was observed in $\mathrm{T}_{1}$. However, the higher $\mathrm{a}^{*}$ (Red to green) value as 2.09 in $\mathrm{T}_{1}$ and lowest $\mathrm{a}^{*}$ value as 1.64 was observed in $\mathrm{T}_{2}$. Whereas, higher $\mathrm{b}^{*}$ (Yellow to blue) value as 49.81 was observed in $\mathrm{T}_{1}$ and lower as in $\mathrm{T}_{2}$. The data in same Table also shows that higher DPPH antioxidant activity $(88.12 \%)$, metal chelating activity $(68.50 \%)$, FRAP $\left(816.10 \mu \mathrm{M} \mathrm{Fe}^{2+} / 100 \mathrm{~g}\right)$ as well reducing power (1.908) was observed in lyophilized phenolic extract of treatment $\mathrm{T}_{1}$ and lower in $\mathrm{T}_{2}$. The significant differences were observed in various antioxidant properties in both the treatments due to variation in time of extraction.

Table 3: Colour and antioxidant properties of lyophilized phenolic extract powder of different treatments (values are average of triplicate replications and are represented as Mean \pm SD)

\begin{tabular}{|c|r|r|}
\hline \multirow{2}{*}{ Parameters } & \multicolumn{2}{|c|}{ Treatments } \\
\cline { 2 - 3 } & $\mathrm{T}_{1}$ & \multicolumn{1}{|c|}{$\mathrm{T}_{2}$} \\
\hline $\mathrm{L}^{*}$ & $90.85 \pm 0.01$ & $91.27 \pm 0.04$ \\
\hline $\mathrm{a}^{*}$ & $2.09 \pm 0.09$ & $1.64 \pm 0.14$ \\
\hline $\mathrm{b}^{*}$ & $49.81 \pm 0.05$ & $48.99 \pm 0.11$ \\
\hline DPPH anti-oxidant activity (\%) & $88.12 \pm 0.31$ & $83.70 \pm 0.80$ \\
\hline Metal chelating activity (\%) & $68.50 \pm 0.43$ & $66.20 \pm 0.65$ \\
\hline FRAP $\left(\mu \mathrm{M} \mathrm{Fe}^{2+} / 100 \mathrm{~g}\right)$ & $816.10 \pm 0.90$ & $620.20 \pm 1.15$ \\
\hline $\begin{array}{c}\text { Reducing power } \\
\text { (Absorbance at } 700 \mathrm{~nm})\end{array}$ & $1.908 \pm 0.04$ & $1.800 \pm 0.09$ \\
\hline
\end{tabular}

$\mathrm{T}_{1}$ : Ethanol extract after $4 \mathrm{~h}$ of extraction by Soxhlet method,

$\mathrm{T}_{2}$ : Ethanol extract after $6 \mathrm{~h}$ of extraction by Soxhlet method, and

*L (Lightness), *a (Red to green), *b (Yellow to blue).

Table 4: Antimicrobial activity of different lyophilized phenolic extracts powder against Staphylococcus aureus and Escherichia coli (values are average of triplicate replications and are represented as Mean \pm SD)

\begin{tabular}{|c|c|c|c|c|}
\hline \multirow{3}{*}{$\begin{array}{c}\text { Treatments } \\
\text { Concentrations }\end{array}$} & \multicolumn{2}{|c|}{ Staphylococcus aureus } & \multicolumn{2}{|c|}{ Escherichia coli } \\
\hline & \multicolumn{2}{|c|}{ Inhibition zone (mm) } & \multicolumn{2}{|c|}{ Inhibition zone (mm) } \\
\hline & $T_{1}$ & $T_{2}$ & $T_{1}$ & $T_{2}$ \\
\hline $\begin{array}{l}25 \mathrm{ppm} \\
50 \mathrm{ppm} \\
75 \mathrm{ppm} \\
100 \mathrm{ppm}\end{array}$ & $\begin{array}{l}14.0 \pm 0.10 \\
17.0 \pm 0.15 \\
20.0 \pm 0.12 \\
22.0 \pm 0.11\end{array}$ & $\begin{array}{l}12.5 \pm 0.20 \\
15.0 \pm 0.18 \\
18.0 \pm 0.10 \\
21.2 \pm 0.20\end{array}$ & $\begin{array}{l}13.2 \pm 0.10 \\
16.5 \pm 0.18 \\
18.0 \pm 0.15 \\
20.0 \pm 0.10\end{array}$ & $\begin{array}{l}13.0 \pm 0.12 \\
14.5 \pm 0.20 \\
17.4 \pm 0.22 \\
18.2 \pm 0.14\end{array}$ \\
\hline
\end{tabular}

$\mathrm{T}_{1}$ : Ethanol extract after $4 \mathrm{~h}$ of extraction by Soxhlet method,

$\mathrm{T}_{2}$ : Ethanol extract after $6 \mathrm{~h}$ of extraction by Soxhlet method. 


\subsection{Antimicrobial activity of lyophilized phenolic extract powder}

The data presented in Table 4 showed that there was a general increasing trend in inhibition zone $(\mathrm{mm})$ of different lyophilized phenolic extracts powder against Staphylococcus aureus with increasing the concentration of extract from $25 \mathrm{ppm}$ to $100 \mathrm{ppm}$. Maximum $(22.0 \mathrm{~mm})$ zone of inhibition against Staphylococcus aureus was found in treatment $\mathrm{T}_{1}$ at $100 \mathrm{ppm}$ concentration, whereas, maximum $(20.0 \mathrm{~mm})$ zone of inhibition against Escherichia coli was found in treatment $T_{1}$ at $100 \mathrm{ppm}$ concentrations. With the increase in concentration of phenolic extract powder, zone of inhibition against Staphylococcus aureus and Escherichia coli increased significantly (Figure 3).

\section{Discussion}

The results highlight the significant effect of extraction solvents and time on the extract yield, total phenolics and flavonoids of wild pomegranate flavedo extract. However, the maximum extract yield was observed after $6 \mathrm{~h}$ of extraction with ethanol $\left(\mathrm{S}_{3}\right)$ which was at par with $\mathrm{S}_{2}$ (ethanol, $4 \mathrm{~h}$ ) and minimum extract yield was observed after $2 \mathrm{~h}$ of extraction with diethyl ether $\left(\mathrm{S}_{10}\right)$ which was closely followed by $S_{11}$ and $S_{12}$. The highest extract yield observed with ethanol, might be due to polar nature of solvent with high dielectric constant (24) as compared to the less or non-polar solvent. The maximum extract yield observed with ethanol after $6 \mathrm{~h}$ of extraction might be due to increased efficiency of the extraction with time, since heat render the cell walls permeable, increases solubility and diffusion coefficients of the compounds to be extracted and decreases the viscosity of the solvent, thus facilitating its passage through the solid substrate mass. Similar trend of extract yield with ethanol, acetone and ethyl acetate by Soxhlet extraction was also recorded by Mehrizi et al. (2017). Similar variation in extract yield was also recorded by Khan and Das (2019) by Soxhlet method. The polarity of the solvents used for extraction is the important factor that affects extract yield (Joshi et al., 2017). While comparing all the treatments, total phenolics content increased with the increase in extraction time when ethanol was used as a solvent, but in all the other solvents, total phenolics content decreased with the increasing extraction time. However, the maximum total phenolics content was observed in ethanol $\left(\mathrm{S}_{3}\right)$ after $6 \mathrm{~h}$ of extraction and minimum total phenolics content was observed in diethyl ether $\left(S_{12}\right)$ after $6 \mathrm{~h}$ of extraction. Highest total phenolics content observed in treatment $\mathrm{S}_{3}$ (ethanol, $6 \mathrm{~h}$ ), might be due to polar protic nature of solvent and higher dielectric constant as compared to the other solvents which leads towards the increase in the amount of total phenolics content. The prolonged extraction time $(6 \mathrm{~h})$ might have further increased the extraction efficiency and increases solubility of compounds in the polar solvent because of their higher dipole moment. Whereas, the lower total phenolics content observed in treatment $S_{12}$ (diethyl ether, $6 \mathrm{~h}$ ) might be due to its non-polar nature of solvent having lower dielectric constant and lower dipole movement as compared to other solvents. A significant effect of extraction time as well as solvent type was observed on total phenolics content of flavedo extract. The polarities of the solvents varied from polar to non- polar and optimum extraction of polyphenols usually obtained in the polar solvents which have a better efficiency of solvation as a result of hydrogen bonds interactions between the polar sites of the antioxidant compounds (Liu et al., 2007). This might be the reason of higher extraction of phenolic compounds in ethanol than non polar diethyl ether. While lower total phenolics content observed in solvents like acetone and ethyl acetate might be due to the lower solubility of phenolics in these solvents due to polar aprotic nature as well as of their lower capability to break covalent molecules into ions. This might be due to the fact that acetone molecules accept the proton only whereas ethanol is a proton donor (Thouri et al., 2017). However, the maximum total flavonoids content was observed in ethanol $\left(\mathrm{S}_{2}\right)$ after $4 \mathrm{~h}$ of extraction and minimum content was observed in diethyl ether $\left(\mathrm{S}_{12}\right)$ after $6 \mathrm{~h}$ of extraction. The higher total flavonoids content recorded in ethanol might be due to the enhanced solubility of flavonoids in polar protic solvents as compared to non polar solvent (diethyl ether). While lower total flavonoids content after $6 \mathrm{~h}$ of extraction might be due to degradation of flavonoids at boiling temperature of solvent for longer time, as temperature above $25^{\circ} \mathrm{C}$ directly affected the flavonoids. Total flavonoids content decreased with repeated extraction for longer time period. This might be due to the destructive effect of higher temperature on total flavonoids, coupled with increased extraction time. The degradation process for flavonoids is an oxidative and temperature dependent. The total flavonoids content observed with ethanol might be due to enhanced solubility of flavonoids in polar protic solvent (ethanol) as compared to other solvents. These differences could be due to the variation in polarities of the solvents, which selectively extract different hydrophobic or hydrophilic phenolic compounds in the sample. As polar solvents have higher dielectric constant and higher dipole movement due to which, higher capability to break covalent molecules into ions. Whereas, the lower total flavonoids content observed with diethyl ether might be due to non-polar nature of this solvent as compared to polar solvents which restricted the extraction of flavonoids.

Further, it is evident from the obtained dendrogram in Figure 2 that different treatments are categorized in a variety of groups and clusters based upon similarity. This is also supported by given Figure 1(a-c) that treatments with higher phenolic content $\left(\mathrm{T}_{2}\right.$ and $\left.\mathrm{T}_{3}\right)$ are placed in one group and treatments with lower phenolic content $\left(\mathrm{T}_{11}\right.$ and $\left.\mathrm{T}_{12}\right)$ are placed in another group. So, on the basis of hierarchical clustering of the data of extract yield, total phenolics and total flavonoids of wild pomegranate flavedo extract, two treatments $\left(\mathrm{T}_{2}\right.$ and $\left.\mathrm{T}_{3}\right)$ from cluster (2) were selected for further studies due to interlinked similarities between these two treatments. The selected treatments were further dried by lyophilization and compared with oven dried samples.

Data in Table 2 reflect that total phenolics content and total flavonoids content were recorded higher in lyophilized samples of all the treatments as compare to oven dried samples. The maximum amount of phenolics and flavonoids in freeze dried extract might be due to the better stability of various antioxidant compounds at low temperature as compared to high drying temperature. Abid et al. (2017) have reported total phenols content as 109.21 to $140.93 \mathrm{mg}$ 
GAE/g in ethanol extract and 157.06 to $304.60 \mathrm{mg} \mathrm{GAE} / \mathrm{g}$ in acetone extract of commercial pomegranate peel by maceration. Total phenols content in ethanol and water extract of commercial pomegranate peel as $449.60 \pm 4.40$ and $380.54 \pm 5.87 \mathrm{mg} \mathrm{GAE} / \mathrm{g}$, respectively by Soxhlet method have been reported by Manasathien et al. (2012). Our results are within the range of phenolics reported by Abid et al. (2017) and Manasathien et al. (2012). So, lyophilized flavedo extract was selected for further studies on the basis of comparatively higher amount of phenolics and flavonoids.

The data in Table 3 also shows that highest DPPH antioxidant activity, metal chelating activity, FRAP as well reducing power was observed in $\mathrm{T}_{1}$ and lowest in $\mathrm{T}_{2}$. The maximum amount of phenolics and flavonoids recorded in $\mathrm{T}_{1}$ in lyophilized wild pomegranate flavedo extract might be due to the better stability of various antioxidant compounds with low temperature as well as higher initial antioxidants values as compared to treatment $T_{2}$. It might be due to redox potential of phenolic compounds plays an important role in determining the antioxidant potential and, hence these polyphenolics showed strong antioxidant activity (Das et al., 2019).

With the increase in concentration of phenolic extract powder, zone of inhibition against $S$. aureus and E. coli also increased significantly. Similar trend of increasing zone of inhibition has been also reported by Mohamed et al. (2018). The maximum zone of inhibition against $S$. aureus and $E$. coli observed in treatment $\mathrm{T}_{1}$ might be due to the presence of higher amount of phenolics and flavonoids in this extract. The other reason might be antimicrobial activities of phenolic compounds involved in multiple modes of action like degradation of cell wall, interaction with the composition and disruption of cytoplasmic membrane (Lambert et al., 2001). Khan and Hanee (2011); Malviya et al. (2014) and Bharani and Namasivayam (2016) have also reported varying zone of inhibition against various microorganisms in different extracts of commercial pomegranate peel. Gunwantrao et al. (2016) have also reported varying zone of inhibition against various microorganisms in different extracts of peel of orange and pineapple fruits.

\section{Conclusion}

It was concluded from our results that the lyophilized ethanolic flavedo extract of wild pomegranate flavedo powder prepared by Soxhlet method after $4 \mathrm{~h}$ of extraction is a potential source of natural phenolic antioxidants and could be used as a source of natural antioxidants as well as food preservative in food. The highest total phenolics, total flavonoids, DPPH free radical scavenging activity, FRAP and metal chelating activity among different extracts of wild pomegranate flavedo were recorded when ethanol was used for extraction $(4 \mathrm{~h})$. The selected lyophilized extract has also high antimicrobial activity against $S$. aureus and E. coli. Hence, on the basis of higher antioxidant properties as well as phenolic and flavonoids content besides antimicrobial activity, this fruit flavedo could be used in development of new functional foods for the prevention of various diseases in future, due to the potential source of natural antioxidants. This research will also be helpful in the development of new nutritional supplements after commercialization and for the development of high antioxidant products besides the major use of fruit arils in 'anardana' production.

\section{Conflict of interest}

The authors declare that there are no conflicts of interest in the course of conducting the research. All the authors had final decision regarding the manuscript and decision to submit the findings for publication.

\section{References}

Abid, M.; Yaich, H.; Cheikhrouhou, S.; Khemakhem, I.; Bouaziz, M.; Attia, H. and Ayadi, M. A. (2017). Antioxidant properties and phenolic profile characterization by LC-MS/MS of selected Tunisian pomegranate peels. Journal of Food Science and Technology, 54:2890-2901.

Benzie, I. F. and Strain, J. J. (1996). Ferric reducing ability of plasma (FRAP) as a measure of antioxidant power: The FRAP assay. Analytical Biochemistry, 239:70-76.

Berrueta, L. A.; Alonso-Salces, R. M. and Heberger, K. (2007). Supervised pattern recognition in food analysis. Journal of Chromatography A., 1158:196-214.

Bharani, R. S. A. and Namasivayam, S. K. R. (2016). Pomegranate (Punica granatum L.) peel extract: A study on potential source of pharmacological activities. International Journal of Pharma and Bio Sciences, 7:282-290.

Brand-Williams, W.; Cuvelier, M. E. and Berset, C. (1995). Use of a free radical method to evaluate antioxidant activity. LWT-Food Science and Technology, 28:25-30.

Das, K.; Khan, M. S.; Namratha, N.; Swetha, R. and Gezici, S. (2019). Comparative phytochemical screening, elemental content and chromatographic evaluation for detection and quantification of polyphenolic compounds for strong antioxidant activity of various extracts of Abutilon indicum (Link) Sweet leaves. Ann. Phytomed., 8:36-44.

Dinis, T. C.; Madeira, V. M. and Almeida, L. M. (1994). Action of phenolic derivatives (acetaminophen, salicylate, and 5-aminosalicylate) as inhibitors of membrane lipid peroxidation and as peroxyl radical scavengers. Archives in Biochemistry and Biophysics, 315:161-169.

Gunwantrao, B. B.; Bhausaheb, S. K.; Ramrao, B. S. and Subhash, K. S. (2016). Antimicrobial activity and phytochemical analysis of orange (Citrus aurantium L.) and pineapple (Ananas comosus (L.) Merr.) peel extract. Ann. Phytomed., 5:156-160.

Ilahy, R.; Hdider, C.; Lenucci, M. S.; Tlili, I. and Dalessandro, G. (2011). Antioxidant activity and bioactive compound changes during fruit ripening of high-lycopene tomato cultivars. Journal of Food Composition and Analysis, 24:588-595.

Joshi, K., Pant, N. C., Kumar, V. A. and Kumar, A. (2017). Antioxidant and antibacterial activities of methanol, ethanol and aqueous extracts of leaf and root of Gentiana kurroo Royle. Ann. Phytomed., 6:138-148.

Khan, J. A. and Hanee, S. (2011). Antibacterial properties of Punica granatum peels. International Journal of Applied Biology and Pharmaceutical Technology, 2:23-27.

Khan, M. S. and Das, K. (2019). Effect of solvents and extractors on proximate analysis, pharmacognostical screening and chromatographic analysis of Decalepis nervosa (Wight and Arn.) Venter leaf: An endangered plant from Western Ghats region. Ann. Phytomed., 8:64-74.

Kher, R. (1999). Note on the physico-chemical characters of wild pomegranate (Punica granatum L.). Annals of Biology, 15:231232. 
Lambert, R. J. W.; Skandamis, P. N.; Coote, P. and Nychas, G. J. E. (2001). A study of the minimum inhibition concentration and mode of action of oregano essential oil, thymol and carvacrol. Journal of Applied Microbiology, 91:453-462.

Liu, X.; Dong, M.; Chen, X.; Jiang, M.; Lv, X. and Yan, G. (2007). Antioxidant activity and phenolics of an endophytic Xylaria sp. from Ginkgo biloba. Food Chemistry, 105:548-554.

Malviya, S.; Jha, A. and Hettiarachchy, N. (2014). Antioxidant and antibacterial potential of pomegranate peel extracts. Journal of Food Science and Technology, 51:4132-4137.

Manasathien, J.; Indrapichate, K. and Intarapichet, K. (2012). Antioxidant activity and bioefficacy of pomegranate Punica granatum Linn. peel and seed extracts. Global Journal of Pharmacology, 6:131-141.

Masci, A.; Coccia, A.; Lendaro, E.; Mosca, L.; Paolicelli, P. and Cesa, S. (2016). Evaluation of different extraction methods from pomegranate whole fruit or peels and the antioxidant and antiproliferative activity of the polyphenolic fraction. Food Chemistry, 202:59-69.

Mehrizi, R. Z.; Emam-Djomeh, Z.; Shahedi, M.; Keramat, J.; Rezaei, K. and Loni, E. (2017). Phenolic compounds and antioxidant activity of dried peel of Iranian pomegranate. Journal of Food Quality and Hazards Control, 4:103-108.
Mohamed, Z.; Ridha, O. M.; Eddine, L. S. and Rebiai, A. (2018). Phenolic content, antioxidant and antibacterial activities of peel extract from Punica granatum L. Research Journal of Chemistry and Environment, 22:9-15.

Murtaza, M. S. and Ahmad, G. S. (2017). Anardana (dehydrated wild pomegranate arils) as livelihood option for rural communities in Chenab valley of Jammu and Kashmir. Indian Journal of Horticulture, 74:306-309.

Oktay, M.; Gulein, I. and Kufrevioglu, O. I. (2003). Determination of in vitro antioxidant activity of fennel (Foeniculum vulgare) seed extracts. LWT-Food Science and Technology, 36:263-271.

Singleton, V. L. and Rossi, J. A. (1965). Colorimetry of total phenolics with phosphomolybedic phosphotungstic acid reagents. American Journal of Enology and Viticulture, 16:144-158.

Thakur, A.; Thakur, N. S.; Hamid and Kumar, P. (2018). Studies on physicochemical and antioxidant properties of wild pomegranate fruits in different locations of Himachal Pradesh, India. International Journal of Current Microbiology and Applied Sciences, 7:2842-2850.

Thouri, A.; Chahdoura, H.; Arem, A. E.; Hichri, A. O.; Hassin, R. B. and Achour, L. (2017). Effect of solvents extraction on phytochemical components and biological activities of Tunisian date seeds (var. Korkobbi and Arechti). BMC Complementary and Alternative Medicine, 17:248.

Citation: Hamid, N. S. Thakur, Rakesh Sharma, Abhimanyu Thakur, Pradeep Kumar and Sunakshi Gautam (2020). Phytochemical extraction and quantification from wild pomegranate flavedo powder, their antioxidant and antimicrobial properties. Ann. Phytomed., 9(1):187-194. http://dx.doi.org/10.21276/ap.2020.9.1.24 